\title{
Editorial: Function of Renal Sympathetic Nerves
}

\author{
Yutang Wang ${ }^{1 *}$, Kyungjoon Lim $^{2}$ and Kate M. Denton ${ }^{3 *}$ \\ ${ }^{1}$ School of Applied and Biomedical Science, Federation University Australia, Ballarat, VIC, Australia, ${ }^{2}$ Neurophysiology, \\ Department of Physiology, Anatomy and Microbiology, La Trobe University, Melbourne, VIC, Australia, \\ ${ }^{3}$ Cardiovascular Disease Program, Department of Physiology, School of Biomedical Sciences, Monash Biomedicine \\ Discovery Institute, Monash University, Clayton, VIC, Australia
}

Keywords: atherosclerosis, heart failure, hypertension, kidney disease, renal denervation, renal sympathetic nerves

Editorial on the Research Topic

Function of Renal Sympathetic Nerves

\section{INTRODUCTION}

Cardiovascular disease (CVD) is the leading cause of mortality and morbidity worldwide. The incidence of CVD is increasing in association with the growing prevalence of hypertension, diabetes, and obesity. This is occurring despite established effective therapies for hypertension. Thus, new methods for risk reduction are still needed (Cutler et al., 2008). The aim of this research topic was to evaluate the efficacy and safety of renal denervation (RDN), to explore the contribution of both afferent and efferent renal nerve activity to hypertension and non-hypertension disorders, and to stimulate future research to better understand the function of the renal nerves and the effects

OPEN ACCESS

Edited and reviewed by: Carolyn J. Barrett, University of Auckland, New Zealand

*Correspondence: Yutang Wang Yutang.wang@federation.edu.au Kate M. Denton

kate.denton@monash.edu

Specialty section:

This article was submitted to Integrative Physiology, a section of the journal Frontiers in Physiology

Received: 05 July 2017 Accepted: 15 August 2017 Published: 28 August 2017

Citation:

Wang Y, Lim K and Denton KM (2017) Editorial: Function of Renal Sympathetic Nerves.

Front. Physiol. 8:642 doi: 10.3389/fphys.2017.00642 of RDN by highlighting gaps in knowledge.

\section{EVALUATION OF CATHETER-BASED RENAL DENERVATION FOR THE TREATMENT OF HYPERTENSION}

Strong evidence that sympathetic overactivity is associated with the development of hypertension, combined with the demonstration that RDN prevents or delays hypertension in a variety of animal models, laid the groundwork for the introduction of RDN as a clinical therapy in humans (DiBona and Esler, 2010). In 2007, a novel, minimally invasive RDN ablation catheter was first trialed in hypertensive patients, with a $93 \%$ success rate of lowering blood pressure (BP) for at least 3 years post-RDN (Krum et al., 2014). These studies were met with acclaim (Lakhanpal and Domanski, 2012). However, a large scale, sham-controlled clinical trial (Symplicity HTN-3) failed to show reductions in BP greater than sham (Bhatt et al., 2014). It is now clear that poor trial design contributed to this outcome; only 19 of the 340 patients received at least the recommended $4+$ ablations per artery and in these patients the falls in BP were greatest (Kandzari et al., 2015). In addition, the report by the Global SYMPLICITY Registry of 1,000 consecutively enrolled patients not only confirmed the safety of RDN but also suggested that RDN lowers office and ambulatory $\mathrm{BP}$ at 6 months post-procedure (Bohm et al., 2015). In the current volume, Fadl Elmula et al. summarizes the results of recent clinical RDN trials and rightly raised concerns regarding the interpretation of this data and called for caution in the implementation of this procedure. The authors point out that these trials did not confirm the marked BP lowering effect observed by initial RDN studies (Krum et al., 2009; Esler et al., 2010). In addition, they suggested that the $\mathrm{BP}$ lowering effect of RDN may be limited to discrete patient populations, and that it would be 
worthwhile searching for potential predictors of true responders to $\mathrm{RDN}$. Briasoulis and Bakris reviewed the role of renal sympathetic nerves in hypertension and clinical applications of RDN in resistant hypertension. In light of the results from the Symplicity HTN-3 trial, the authors suggested that future randomized trials should be performed in experienced centers, using newer catheters, and in carefully selected compliant patients with true resistant hypertension.

\section{EFFECTS OF RENAL DENERVATION BEYOND BLOOD PRESSURE CONTROL}

It is noteworthy that RDN has also been shown to be effective in the treatment of other conditions coexisting with resistant hypertension. Thorp and Schlaich contributed a comprehensive review on RDN for hypertension and beyond. The nonhypertensive disorders that may also be affected by RDN include chronic kidney disease, chronic heart failure, left ventricular hypertrophy, arrhythmias, and metabolic diseases. Evidence suggests that clinical benefits beyond $\mathrm{BP}$ reduction could be gained following RDN in patients with these disorders. However, randomized controlled trials are needed before the application of $\mathrm{RDN}$ becomes routine in clinical practice for these patient cohorts. Moreover, these intriguing findings suggest that there is still a lot we don't understand about the function of the renal nerves.

\section{Heart Failure}

The kidney has a rich afferent sensory and efferent sympathetic innervation. It is now apparent that afferent renal nerve activity can reflexly modulate sympathetic outflow, not just to the kidney, but also to other organs, which may be one mechanism whereby RDN might improve outcomes in heart failure. Ramchandra and Barrett reviewed the mechanisms that contribute to enhanced renal sympathetic nerve activity (SNA) during heart failure, with an emphasis on afferent reflexes and central mechanisms. Booth et al. also contributed a review on this topic, focusing on critically assessing recent preclinical and clinical evidence supporting $\mathrm{RDN}$ as a potential treatment for heart failure. It was concluded that a reflex reduction in cardiac SNA in heart failure may be one beneficial effect of RDN. Booth et al. also explored the effect of RDN on the renal afferents, and provided evidence for both the destruction and then significant regrowth of afferent renal nerves. However, what effect ablating the afferent nerves play in mediating the responses to RDN is still largely unknown. Finally, Schiller et al. (2015) reviewed the contribution of renal nerves to the pathogenesis of chronic heart failure, providing an overview of clinical RDN studies to date. This culminated in a call for more research to determine how RDN may be employed as a safe and effective treatment in chronic heart failure.

\section{Kidney Disease}

Strong evidence demonstrates that renal SNA is elevated in both acute and chronic kidney disease. Although less robust, evidence also implicates increased afferent sensory nerve activity in kidney disease. In a primary study, Salman et al. demonstrated using telemetry-based recordings in rats with chronic kidney disease
(Lewis Polycystic Kidney rats) that renal SNA directly correlated with BP. This study confirmed the notion that elevated renal SNA is likely a key contributor to hypertensive kidney disease. In an acute study, Goulding et al. examined the contribution of the renal nerves to baroreflex control of renal SNA and excretory function in cisplatin-induced renal failure in rats. The authors found that impaired renal function was associated with blunting of baroreflex gain and increased renal SNA, and that RDN restored these abnormalities. The results of this study suggested that dysregulation of renal SNA plays an important role in renal failure and that $\mathrm{RDN}$ may provide benefits for patients with kidney disease. In combination, this evidence led to the suggestion that kidney disease may also be amenable to RDN and Sanders and Blankestijn contributed a review of the clinical evidence arguing that RDN may have a place in the management of chronic kidney disease. RDN has been trialed in models of chronic kidney disease and been shown to be effective in lowering BP, though concerns were raised regarding the ability to adequately mount a response to hemorrhage (Singh et al., 2017).

\section{LONG-TERM SAFETY CONCERNS FOLLOWING RDN}

The introduction of catheter-based RDN initially moved forward at a rapid pace and though this has slowed, interest still remains strong. In part, this reduced momentum stems from concerns surrounding the lack of understanding of the long-term impact of $\mathrm{RDN}$. Wang pointed out that although RDN is generally regarded as a safe procedure, some reports with small sample size have shown that the incidence of renal artery stenosis after RDN could be up to $18.2 \%$; though this may depend on operator experience and the type of catheter employed. However, the safety of RDN needs to be continuously monitored.

In another study, Wang et al. examined the possible side effects of RDN in apolipoprotein E-deficient mice with hypertension induced by angiotensin II infusion. It was found that $\mathrm{RDN}$ increased atherosclerosis in the aortic arch despite a reduction in systolic $\mathrm{BP}$ in the mice. In contrast, $\mathrm{RDN}$ has been reported to decrease atherosclerosis in normotensive apolipoprotein E-deficient mice fed a high fat diet (Wang et al., 2015). Therefore, whether RDN promotes atherosclerosis in patients with resistant hypertension requires investigation in follow-up studies. In fact, the consequences of RDN in all patient populations in which this procedure is being trialed requires longer term follow-up, given evidence that the renal nerves regrow over time (Booth et al., 2015).

\section{CONCLUSION}

Thus, the articles contained in this collection, contribute to our understanding of the function of the renal nerves, the effects of RDN as a treatment for hypertension and non-hypertensive disorders, and the side effects of RDN. However, much remains to be learned in terms of intra-procedural verification of the 
completeness of RDN, patient selection and long-term safety of RDN.

\section{AUTHOR CONTRIBUTIONS}

$\mathrm{YW}, \mathrm{KL}$, and $\mathrm{KD}$ conceived the content. YW drafted the manuscript. KL and KD revised the manuscript.

\section{REFERENCES}

Bhatt, D. L., Kandzari, D. E., O’Neill, W. W., D’Agostino, R., Flack, J. M., Katzen, B. T., et al. (2014). A controlled trial of renal denervation for resistant hypertension. N. Engl. J. Med. 370, 1393-1401. doi: 10.1056/NEJMoa1 402670

Bohm, M., Mahfoud, F., Ukena, C., Hoppe, U. C., Narkiewicz, K., Negoita, M., et al. (2015). First report of the Global SYMPLICITY Registry on the effect of renal artery denervation in patients with uncontrolled hypertension. Hypertension 65, 766-774. doi: 10.1161/HYPERTENSIONAHA.114. 05010

Booth, L. C., Nishi, E. E., Yao, S. T., Ramchandra, R., Lambert, G. W., Schlaich, M. P., et al. (2015). Reinnervation of renal afferent and efferent nerves at 5.5 and 11 months after catheter-based radiofrequency renal denervation in sheep. Hypertension 65, 393-400. doi: 10.1161/HYPERTENSIONAHA.114. 04176

Cutler, J. A., Sorlie, P. D., Wolz, M., Thom, T., Fields, L. E., and Roccella, E. J. (2008). Trends in hypertension prevalence, awareness, treatment, and control rates in United States adults between 1988-1994 and 19992004. Hypertension 52, 818-827. doi: 10.1161/HYPERTENSIONAHA.108. 113357

DiBona, G. F., and Esler, M. (2010). Translational medicine: the antihypertensive effect of renal denervation. Am. J. Physiol. Regul. Integr. Comp. Physiol. 298, R245-253. doi: 10.1152/ajpregu.00647.2009

Esler, M. D., Krum, H., Sobotka, P. A., Schlaich, M. P., Schmieder, R. E., and Bohm, M. (2010). Renal sympathetic denervation in patients with treatment-resistant hypertension (The Symplicity HTN-2 Trial): a randomised controlled trial. Lancet 376, 1903-1909. doi: 10.1016/S0140-6736(10) 62039-9

Kandzari, D. E., Bhatt, D. L., Brar, S., Devireddy, C. M., Esler, M., Fahy, M., et al. (2015). Predictors of blood pressure response in the SYMPLICITY HTN-3 trial. Eur. Heart J. 36, 219-227. doi: 10.1093/eurheartj/ehu441

\section{ACKNOWLEDGMENTS}

YW is supported by a grant from the National Health and Medical Research Council (1062671). KL is supported by a grant from La Trobe University (Understanding Disease RFA). KD is supported by an NHMRC Research Fellowship (1041844).

Krum, H., Schlaich, M. P., Sobotka, P. A., Bohm, M., Mahfoud, F., Rocha-Singh, K., et al. (2014). Percutaneous renal denervation in patients with treatmentresistant hypertension: final 3-year report of the Symplicity HTN-1 study. Lancet 383, 622-629. doi: 10.1016/S0140-6736(13)62192-3

Krum, H., Schlaich, M., Whitbourn, R., Sobotka, P. A., Sadowski, J., Bartus, K., et al. (2009). Catheter-based renal sympathetic denervation for resistant hypertension: a multicentre safety and proof-of-principle cohort study. Lancet 373, 1275-1281. doi: 10.1016/S0140-6736(09)60566-3

Lakhanpal, J. R., and Domanski, M. J. (2012). Hypothesis: catheter-based renal sympathetic denervation should be the initial therapy for essential hypertension. Med. Hypotheses 78, 482-484 doi: 10.1016/j.mehy.2012.01.011

Schiller, A. M., Pellegrino, P. R., and Zucker, I. H. (2015). The renal nerves in chronic heart failure: efferent and afferent mechanisms. Front. Physiol. 6:224. doi: 10.3389/fphys.2015.00224

Singh, R. R., Sajeesh, V., Booth, L. C., McArdle, Z., May, C. N., Head, G. A., et al. (2017). Catheter-based renal denervation exacerbates blood pressure fall during hemorrhage. J. Am. Coll. Cardiol. 69, 951-964. doi: 10.1016/j.jacc.2016.12.014

Wang, H., Wang, J., Guo, C., Luo, W., Kleiman, K., and Eitzman, D. T. (2015). Renal denervation attenuates progression of atherosclerosis in apolipoprotein E-deficient mice independent of blood pressure lowering. Hypertension 65, 758-765. doi: 10.1161/HYPERTENSIONAHA.114.04648

Conflict of Interest Statement: The authors declare that the research was conducted in the absence of any commercial or financial relationships that could be construed as a potential conflict of interest.

Copyright (c) 2017 Wang, Lim and Denton. This is an open-access article distributed under the terms of the Creative Commons Attribution License (CC BY). The use, distribution or reproduction in other forums is permitted, provided the original author(s) or licensor are credited and that the original publication in this journal is cited, in accordance with accepted academic practice. No use, distribution or reproduction is permitted which does not comply with these terms. 